\title{
A perspectiva dialógica na formação de professores
}

\author{
The dialogical perspective in teacher training \\ La perspectiva dialógica en la formación de profesores
}

LUCICleide ARAúJo de SOUSA Alves (iD ${ }^{a}$

LUIZ SÍVERES (iD ${ }^{b}$

\section{Resumo}

Apresenta caminhos metodológicos na formação de professores, tendo como eixos norteadores os sete saberes requeridos para o futuro (MORIN, 2010), e como dinâmica transversal deste percurso, o diálogo. O diálogo sendo compreendido como um jeito de ser (dialógico), uma maneira de saber (dialético) e uma forma de agir (dialogicidade). Optou-se pela pesquisa qualitativa, por privilegiar os conhecimentos significativos, que em diálogo com os sentidos atribuídos pelos professores em suas vivências e experiências, refletem em atitudes concretas e de valorização da pluralidade cultural entre os distintos saberes. Vinte docentes participaram da pesquisa e integram o Grupo de Pesquisa "Comunidade Escolar Encontros e Diálogos Educativos". Eles atuam em disciplinas de áreas específicas e frequentam o curso de mestrado e doutorado em uma instituição particular, do Distrito Federal. Utilizou-se dos seguintes procedimentos: a revisão bibliográfica e a aplicação de dois questionários: o primeiro com uma questão fechada, e o segundo com uma questão aberta que foi respondida por meio de narrativas. Produzidos os dados, estes foram analisados e categorizados segundo o processo de "análise de conteúdo" (BARDIN, 2002), sob o olhar dos sete saberes e baseado

\footnotetext{
a Universidade Católica de Brasília (UCB), Brasília, DF, Brasil. Doutora em Psicologia, e-mail: lucicleide.ead@gmail.com

${ }^{\mathrm{b}}$ Universidade Católica de Brasília (UCB), Brasília, DF, Brasil. Doutor em Desenvolvimento Sustentável, e-mail: luiz.siveres@gmail.com
} 
no princípio dialógico, segundo Morin (2007). Concluiu-se que a reorganização do espaço pedagógico, com foco na valorização das histórias de vida dos sujeitos e de suas relações de aprendizagem, tendo o diálogo como princípio fundante e regenerador, constitui uma das vias possíveis para propiciar as condições necessárias de gestão, valorizando-se os pensamentos e ações, para que possibilitem a concretude do fazer pedagógico revolucionário e transformador.

Palavras-chave: Formação de professores. Sete saberes. Perspectiva dialógica.

\begin{abstract}
It presents methodological paths in teacher training, having as its guiding axes the seven knowledges required for the future (Morin, 2010), and as a transversal dynamic of this course, dialogue. Dialogue being understood as a way of being (dialogical), a way of knowing (dialectic) and a way of acting (dialogicity). Qualitative research was chosen because it privileges the significant knowledge that, in dialogue with the senses attributed by the teachers in their experiences and experiences, reflects in concrete attitudes and appreciation of the cultural plurality between the different knowledges. Twenty teachers participated in the research and are part of the Research Group "School Community - Educational Meetings and Dialogues". They work in disciplines of specific areas and attend the masters and doctorate courses at a private institution in the Federal District. The following procedures were used: the bibliographic review and the application of two questionnaires: the first with a closed question, and the second with an open question that was answered through narratives. These data were analyzed and categorized according to the "content analysis" process (BARDIN, 2002), based on the seven knowledge and based on the dialogical principle, according to Morin (2007). It was concluded that the reorganization of the pedagogical space, focusing on the valuation of the subjects' life histories and their learning relations, having dialogue as a founding and regenerating principle, is one of the possible ways to provide the necessary management conditions, valuing the thoughts and actions, so that they make possible the concreteness of the revolutionary and transformative pedagogical doing.
\end{abstract}

Keywords: Teacher training. Seven knowledge. Dialogical perspective.

\title{
Resumen
}

En el caso de los profesores, los directores de la escuela, los profesores, los profesores, los alumnos y los alumnos. El diálogo es comprendido como una forma de ser (dialógico), una manera de saber (dialéctico) y una forma de actuar (dialogicidad). Se optó por la investigación cualitativa, por privilegiar los conocimientos significativos, que en diálogo con los sentidos atribuidos por los profesores en sus vivencias $y$ experiencias, reflejan en actitudes concretas y de valorización de la pluralidad cultural entre los distintos saberes. Veinte docentes participaron de la investigación e integran el 
Grupo de Investigación 'Comunidad Escolar - Encuentros y Diálogos Educativos'. Ellos actúan en disciplinas de áreas específicas y frecuentan el curso de maestría y doctorado en una institución particular, del Distrito Federal. Se utilizó de los siguientes procedimientos: la revisión bibliográfica y la aplicación de dos cuestionarios: el primero con una cuestión cerrada, y el segundo con una cuestión abierta que fue respondida por medio de narrativas. En el caso de los países de la Unión Europea, los Estados miembros de la Unión Europea (UE) y los Estados miembros de la Unión Europea (UE). Se concluyó que la reorganización del espacio pedagógico, con foco en la valorización de las historias de vida de los sujetos y de sus relaciones de aprendizaje, teniendo el diálogo como principio fundante y regenerador, constituye una de las vías posibles para propiciar las condiciones necesarias de gestión, valorizando -se los pensamientos y acciones, para que posibiliten la concreción del hacer pedagógico revolucionario y transformador.

Palabras clave: Formación de profesores. Siete saberes. Perspectiva dialógica.

\section{Introdução}

O cenário mundial se apresenta, no alvorecer do novo século, com uma tendência cada vez mais globalizada, seja pelos grupos econômicos, pelos sistemas políticos ou pelas redes sociais. Por outro lado, percebe-se uma dinâmica de fragmentação, seja pela unilateralidade individual, pela polaridade conjuntural ou pela desigualdade social. Tais características podem ser percebidas, principalmente, no nível pessoal, educacional e social e, por isso, esta realidade tem se configurado como um desafio para os pesquisadores contemporâneos, bem como para os professores em formação, que, dispostos a inovar, têm pensado e repensado suas jornadas pedagógicas e epistemologias, mediante processos formativos “autopoiéticos" (MATURANA e VARELA, 2001) no sentido de ato criativo, de elaborações e reelaborações a partir das próprias vivências de experiências de vida, na vida educativa, sob a perspectiva dialógica baseada no pensamento complexo.

Estas características, de uma forma ou de outra, têm influenciado todos os setores da sociedade e, de modo especial, a dinâmica relacional. Isto já foi constatado por Buber (2001), ao afirmar que a humanidade estaria fortalecendo o antidiálogo; por Habermas (2012), porque estaríamos instrumentalizando a razão e, em consequência, instrumentalizando os processos comunicacionais; e por Freire 
(1987), porque as relações sociais estariam sendo pautadas pelo monólogo. Estes argumentos revelam, portanto, a necessidade de retomarmos a abordagem teórica, a reflexão e a prática do diálogo como um dos princípios fundantes e constitutivos para contribuir com processos educacionais formativos trans-formadores.

Embora existam muitas alternativas de formação, este artigo tem por objetivo compreender o diálogo como um procedimento transversal, propor alguns encaminhamentos, tendo como eixos norteadores do percurso os sete saberes necessários à educação do futuro e do presente propostos por Morin (2010), em vista de poder contribuir com a formação de docentes para a qualificação profissional e o compromisso social no contexto da realidade contemporânea.

O diálogo é a base para o processo de cognição em processos de formação humana e, portanto, urgente e necessário. Neste sentido, estamos sugerindo que o diálogo possa ser um elemento motivador e articulador do processo de formação de professores, para se compreender a importância da presença viva do humano na vida e de sua interferência social, mediada por uma ética responsável para consigo, com o outro e com o planeta.

Os procedimentos metodológicos aqui pensados foram produzidos no sentido de garantir possíveis deslocamentos em relação ao papel dos educadores, que nos seus projetos formativos não foram contemplados para caracterizar o diálogo como um princípio e uma mediação do processo de ensino e aprendizagem, bem como no exercício da docência ou na formação continuada. Esta constatação foi percebida, principalmente, na participação dos autores na Conferência Internacional: "Saberes para uma cidadania planetária” (UNESCO, 2016), cujo contexto os mobilizou a pensar e elaborar processos teóricos em sintonia com a práxis, com base nos seguintes questionamentos: Frente aos contextos educativos atuais, com vistas à necessidade de uma reforma no pensamento, de que forma professores e alunos poderiam se distanciar de um pensamento monológico e praticar uma educação baseada na relação dialógica? Como sair das "gaiolas epistemológicas", para construir, de forma dialógica, um conhecimento pertinente? E como reverter o modelo disciplinar, baseado na fragmentação, e sugerir um conhecimento inter ou transdisciplinar? Em outros termos, como romper com o espaço enquadrado, o saber engaiolado e o conhecimento disciplinado no processo de formação de professores? 
Para a tessitura desse processo, numa analogia compreendida como fios para a constituição de uma trança, é mais que requerida a necessidade para esse tecer, de uma educação permeada pelo diálogo, bem como a constituição de subjetividades e intersubjetividades a partir de uma constante dialogicidade entre os mundos intra e interpsíquicos, que se mostram, simultânea e sincronicamente, como princípio e processo na formação de professores.

Neste sentido, inicialmente será apresentado o diálogo como uma dinâmica transversal e, na sequência, uma breve síntese sobre os sete saberes e como esses saberes poderiam se caracterizar como fios que se entrelaçariam para uma formação de professores, no presente e no futuro. Por fim, sob a iluminação dos saberes emergentes suscitados a partir da análise das narrativas proferidas pelos professores, por meio das vivências de suas experiências pedagógicas, será feita uma vinculação com o pensamento complexo, sob a perspectiva dialógica.

\section{O diálogo como uma dinâmica transversal}

O diálogo como uma dinâmica transversal será compreendido como um jeito de ser (dialógico), uma maneira de saber (dialético) e uma forma de agir (dialogicidade). É uma proposta pedagógica alternativa que se justifica em função do contexto social e, em decorrência, do projeto educacional que tem se apresentado mediante acentuadas características unilaterais, polarizantes e fragmentadas. Por esta razão, será compreendida tridimensionalmente a partir da relação antropológica, epistemológica e pedagógica, respectivamente, pois a partir dessas dimensões é possível se transformar numa sugestão relevante para a formação de professores no contexto contemporâneo.

Considerando, portanto, que o diálogo é um princípio inerente à condição humana, o mesmo tem contribuído com a constituição histórica de cada pessoa e com a construção civilizatória da sociedade. Isto é, o diálogo constitui o ser humano que, por sua vez, é constituinte da sociedade, e nesta dinâmica interrelacional a humanidade se revela, desenvolve e se projeta por meio do diálogo.

No exercício da dialógica, segundo Buber (2001), todo ser humano articula a vivência na experiência e esta naquela. Nesta relação de reciprocidade é preciso levar em conta a plenitude da relação que acontece entre o Eu-Tu e a efemeridade da 
disposição que se realiza entre o Eu-Isso sob a perspectiva de Buber (2001). A vivência é tudo que envolve a inteireza do ser, a possibilidade relacional e a dinâmica de sentido para a vida. A experiência é tudo o que se pode observar, explicar ou dominar, ainda que provisoriamente. Assim, a vivência do Eu-Tu estaria mais próxima da singularidade de cada ser, do percurso de sua historicidade e da finalidade do seu projeto de vida. Enquanto a experiência do Eu-Isso estaria retratada na familiaridade com a "tecnologia" (LEMOS, 2004), com os contatos estabelecidos e com as metas que se deseja alcançar.

Nesta perspectiva, o diálogo entre a vivência e a experiência é fundamental para constituir o ser humano e a sociedade (unitas multiplex), porque por meio dessas polaridades, não contrárias, mas complementares, explicita-se a condição humana que expressa suas inúmeras virtualidades, entre elas, como seres de relação, que estão em constante conexão e em profundo vínculo existencial. Do estabelecimento dessa dinâmica relacional entre a vivência e a experiência, o ser humano se constituirá como um ser dialógico, desenvolvendo-se por meio de experiências de vida mais integrada e polifônica. Esta relação entre a vivência (Eu-Tu) e a experiência (Eu-Isso), foi, em grande parte, a desencadeadora de toda a reflexão proposta por Buber (1987) sobre o processo de diálogo nos últimos tempos.

Portanto, para esta proposta de caminho de formação de professores, o diálogo será compreendido nesta dimensão de dinâmica transversal que acontece mediante a relação que ocorre entre o sujeito consigo mesmo, com o outro e com o transcendente, tendo como eixos articuladores os sete saberes necessários para a educação do presente e do futuro, convergindo, conforme a proposta buberiana, por compreender o ser humano como um ser social, de relação, com possibilidades de produzir conhecimento e de atuação consciente na sua comunidade local e na sociedade global.

\section{Os sete saberes necessários à educação do presente e do futuro}

Os sete saberes propostos por Morin (2010) serão os eixos-base para esta formação de professores, entrelaçados pelas sete disposições apresentadas por Nóvoa (2016) e as vivências de profissionais da área educativa que estão comprometidos com a transformação da educação, compõem as referências desta reflexão. 
Estas três contribuições — compreendidas pela analogia de uma trança serão consideradas para identificar cada um dos saberes, bem como suas emergências durante o exercício da profissão docente, seja no decurso de sua formação inicial ou continuada. Embora nosso olhar esteja sempre voltado para o conjunto destes saberes, é oportuno, porém, apresentar uma pequena percepção sobre cada um destes saberes.

As cegueiras do conhecimento: o erro e a ilusão: É importante o reconhecimento de que todo conhecimento comporta o risco do erro e da ilusão. Portanto, não há conhecimento que não esteja ameaçado por esta dupla face. Todo ele é tradução e reconstrução sob a vista de um ponto, não traduzindo o real como visão única, mas compreendendo-o a partir de suas múltiplas facetas de verdades provisórias, cuja interpretação pode ser feita sob os mais diversos olhares e diferentes ângulos, pois a própria realidade apresenta-se sob os contextos multidimensionais.

Os principios do conbecimento pertinente: É o conhecimento processado, refletido, organizado e traduzido na conjunção, permitindo a integração entre o todo (sociedade) e as partes (indivíduo), imbricados com o processo de vida. Este conhecimento é demarcado por um tempo e lugar e, em um momento histórico, com vistas a manter a dinâmica sócio-histórica-cultural da humanidade caminhante. Ele busca estabelecer os elos necessários entre os mais diferentes saberes, permitindo a percepção da realidade sob a visão de conjunto e não fragmentada, pois recoloca o conhecimento aprendido no contexto.

Ensinar a condição humana: Este é um dos principais saberes necessários para o desfrute de uma vida em plenitude. Ensinar a condição humana é compreender a unidade (humano) na diversidade (cultura) humana e esta naquela, para o desenvolvimento conjunto das autonomias individuais, das participações comunitárias e do sentimento de pertencimento do sujeito, posicionando-se no mundo. É conhecer o humano, situando-o no contexto e não fora de sua realidade.

Ensinar a identidade terrena: Ensinar a identidade terrena é perceber-se parte constitutiva dessa sociedade complexa para ser capaz de enfrentar com autonomia as suas incertezas. Já dizia Pascal, citado por Morin (2008, p. 25): “considero impossível conhecer as partes sem conhecer o todo, assim como conhecer o todo sem conhecer, particularmente, as partes [...]”. 
Enfrentar as incertezas: É importante que estejamos prontos a enfrentar as incertezas do conhecimento, pois toda tradução é um ponto de vista (BOFF, 1997), que possivelmente pressupõe erro. No entanto, erro este que pressupõe ponto de partida para novos acertos e erros, possibilitando um caminhar que não se encerra em si mesmo, mas que estará sempre renascendo, mantendo o sujeito em sua dinâmica processual construtiva de conhecimento, aprendendo a conviver com as certezas do conhecimento, ainda que provisórias.

Ensinar a compreensão: "Educar para a compreensão humana", traduz-se em colocar-se no lugar do outro e não desejar para o outro o que não se desejaria para si mesmo. Ou seja, uma compreensão que parte do eu (de si mesmo) para o tu (o outro) legitimando-O.

A ética do gênero bumano: A consciência de nossa identidade como seres pertencentes a um todo se embasaria na ética da compreensão caracterizada pelo "pensar bem", vinculado a ética da compreensão entre as pessoas à ética da era planetária.

Repensar a formação de professores, sob o olhar dos sete saberes propostos por Edgar Morin, pode contribuir para a ressignificação dos atuais contextos educativos, com vistas à superação da prática pedagógica voltada exclusivamente para o ensino, prevalecendo a perspectiva positivista, para a complexa, que privilegia a religação entre a cultura científica e a humanística.

\section{Metodologia}

$\mathrm{Na}$ perspectiva de avançarmos na formação de professores, tendo o diálogo como o fio transversal e entrelaçado pelos sete saberes, as sete disposições e vivências de professores, fizemos opção pela pesquisa qualitativa, por esta privilegiar os conhecimentos significativos que, em diálogo com os sentidos atribuídos pelos professores em suas vivências e experiências, refletem em atitudes concretas e de valorização da pluralidade cultural entre os distintos saberes. Este tipo de pesquisa vai além da visão positivista e de seus parâmetros epistemológicos, por trazer de volta ao seu fazer pedagógico o sujeito e sua subjetividade, ao dar ênfase na 
construção de processos formativos, mediante às representações, os significados e o sentido existencial elaborado, segundo Lemos (2004).

Os docentes participantes da pesquisa integram o Grupo de Pesquisa "Comunidade Escolar — Encontros e Diálogos Educativos". Eles atuam em disciplinas de áreas específicas e frequentam o curso de mestrado e doutorado em uma instituição particular, de caráter confessional e comunitário, do Distrito Federal.

Para a produção dos dados, utilizamo-nos dos seguintes procedimentos: a revisão bibliográfica e a aplicação de dois questionários: o primeiro com uma questão fechada, e o segundo com uma questão aberta que foi respondida por meio de narrativas.

O primeiro questionário foi encaminhado aos 20 participan9tes do Grupo de Pesquisa com a seguinte questão: Considerando a sua compreensão e sua prática educativa, com qual dos sete saberes, propostos por Morin, você mais se identifica? Indique em ordem de prioridade, de 1 a 3 , os três saberes que estariam mais próximos da sua experiência de vida.

Do total dos 20 participantes do grupo, 16 responderam ao questionamento acima, cujos dados seguem descritos na sequência:

\section{Gráfico 1 - Questionário}

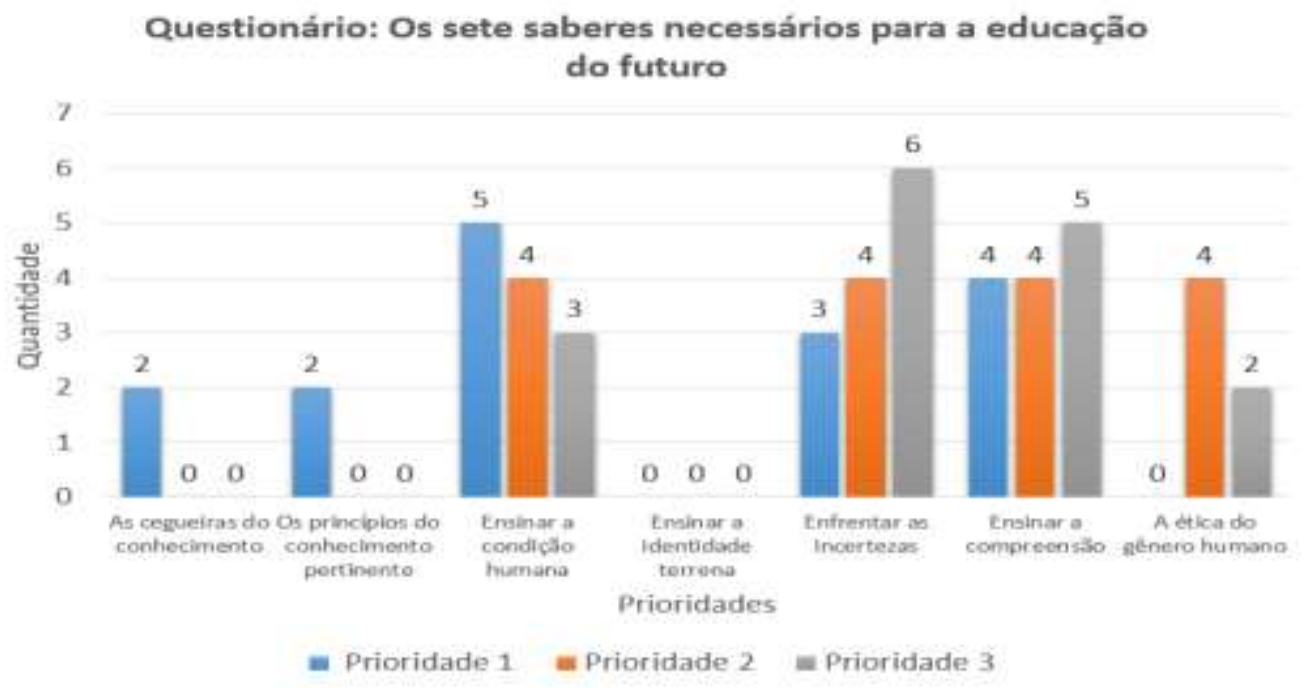

Fonte: Acervo dos autores. 
Segundo o Gráfico 1, todos os saberes receberam algum tipo de menção, exceto o "ensinar a identidade terrena". O conjunto dos dados revela que os três saberes mais apontados, incluindo a indicação de alguma prioridade, foram: ensinar a condição humana, enfrentar as incertezas e ensinar a compreensão. Assim, no ensinar a condição humana, 5 indicaram como prioridade 1, 4 a prioridade 2 e 3 a prioridade 3 , totalizando 12 manifestações. No saber enfrentar as incertezas, 3 responderam como prioridade 1, 4 a prioridade 2 e 6 como prioridade a 3. Por fim, no ensinar a compreensão, 4 respondentes informaram como prioridade 1, 4 como prioridade 2 e 5 como prioridade 3 , resultando também em 13 indicações.

A partir da aplicação do primeiro questionário, os dados gerados revelaram que alguns saberes são prioritários em relação aos demais. Por isso, com base na resposta ao primeiro questionário, optou-se por aprofundar, na análise e discussão, apenas os três saberes mais reconhecidos, a saber: ensinar a condição humana, enfrentar as incertezas e ensinar a compreensão.

Após tomada essa decisão, foi encaminhado o segundo questionário aos 12 participantes que indicaram como primeira prioridade um dos três saberes mais recorrentes. Assim, foi encaminhada a seguinte questão: Com base na sua resposta, gostaríamos de convidá-lo novamente para relatar uma experiência educativa. Para o primeiro grupo foi solicitado uma experiência de "como ensinar a condição humana", para o segundo, "como enfrentar as incertezas", e ao terceiro, "como ensinar a compreensão".

Produzidos os dados nessa segunda etapa, estes foram categorizados e analisados, segundo o processo de análise de conteúdo baseado em Bardin (2002), sob o olhar dos sete saberes e na perspectiva baseada no princípio dialógico, segundo Morin (2000, 2007). Partiu-se da leitura de todo o material, na busca por significados que emergissem das falas como atribuições dos sujeitos a suas próprias ações, de forma a auxiliar nas interpretações a serem discutidas teoricamente. Os temas foram interpretados no seu conjunto, estabelecendo-se relações com o referencial teórico adotado, mas foram selecionados apenas três depoimentos, vinculados aos três saberes mais evidenciados. 


\section{Resultados e discussões}

No sentido de contribuir com o enfrentamento dos desafios da educação contemporânea, por meio de ações concretas que possam incorporar os saberes na prática formativa de professores, foram acolhidas as manifestações de três participantes do Grupo de Pesquisa, ora identificados com nomes de uma família bíblica: Marta, Maria e Lázaro, com o objetivo de resguardar a sua identidade. Assim, foi acolhido o relato de Maria: Ensinar a condição humana, de Lázaro: Enfrentar as incertezas, e Marta: Ensinar a compreensão. Segue a descrição das narrativas:

Como ensinar a condição humana? Eis a reflexão de Maria:

O presente relato versa sobre um trabalho da disciplina Gestão das Instituições Educativas e Esportivas na Licenciatura em Educação. [...]. Como parte da citada disciplina, os estudantes de Educação Física visitaram, durante um semestre uma escola, realizando observações e entrevistas com professores e alunos. Após as primeiras visitas, identificaram que o público atendido reunia alunos de diferentes setores sociais (inclusive alguns moravam em abrigos prévios à espera de adoção), religiões e de diversas nacionalidades (17 países, incluindo República Dominicana, Cuba, Venezuela, Síria, México, Bulgária e outras nações limítrofes). Paralelamente, observaram que a instituição carecia de jogos ou espaços recreativos no pátio escolar, totalmente pintado de cinza. As impressões registradas durante os recreios eram de que os alunos permaneciam isolados. A não existência de áreas recreativas - árvores, gramados, bancos, brinquedos - deixava a instituição muito similar a um cárcere [...]. A partir desse diagnóstico, decidiu-se, de forma coletiva, pela elaboração de um projeto de criação/pintura de jogos, que também contribuiria para fortalecer o senso de pertencimento à instituição escolar - até então pouco consolidado. Os alunos da escola foram indagados sobre as atividades recreativas mais frequentes em seus países de origem, capazes de serem recriadas no pátio escolar. Uma vez realizada a seleção de jogos (amarelinhas, labirintos, redes para esportes coletivos, xadrez, minhocas), os professores de Artes e Recreação foram convidados para colaborar no desenho e execução do projeto batizado de "Pintada na Escola $n^{\circ} 3^{3}$ ". Uma semana depois que a ornamentação da área de lazer foi concluída, realizou-se uma quermesse de inauguração dos espaços recreativos do pátio, reunindo a comunidade escolar mais os estudantes de Educação Física. Música, cores, animação e integração entre os alunos e estudantes mostraram a relevância da aproximação com o outro: escutar suas vozes, identificar suas necessidades. Assim, uma disciplina, em princípio teórica, se transformou numa ágora de integração, não apenas de saberes (gestão, artes, recreação), como também de integração da docência, da pesquisa e da extensão. E, sobretudo, de culturas, biografias e esperanças de que naquela escola é possível aprender e resgatar o sentimento de pertencer à própria comunidade escolar.

Como enfrentar as incertezas? Segue o depoimento de Lázaro: 
O cenário que ora se apresenta é aquele no qual as tecnologias funcionam quase como um dos membros do corpo humano. Aliado a isso, a motivação dos estudantes passou a ser um dos desafios para o processo de ensino e aprendizagem. [...]. Fui tomado pela incerteza sobre qual método de ensino seria considerado o ideal para o alcance dos objetivos propostos a partir de uma experiência vivenciada no início de um semestre letivo. Naquela oportunidade, escutei de alguns dos alunos relatos do tipo "nem mesmo eu sei o que estou fazendo aqui"; enquanto outro dizia: "vou ficar aqui para ver o que dá..."; teve ainda: "não sei se vou aguentar até o fim". Diante dessa situação de incerteza acerca de quais eram os objetivos de parte daquele grupo, procurei refletir na tentativa de responder à seguinte questão: como aplicar técnicas de ensino que pudessem motivar esses estudantes, face às incertezas e quanto à possível eficácia ou fracasso da estratégia por mim escolhida.

Como ensinar a compreensão? Segue o relato de Marta:

Esse relato de experiência versa sobre um processo interventivo de Gestão Escolar, constituído num esforço educativo de abrir possibilidades de humanização, cooperação, e reflexão do papel do gestor e da comunidade escolar em busca do fazer coletivo e democrático. Teve como espaço uma instituição de Educação Básica no Distrito Federal entre os anos de 2011 a 2016, localizada em área urbana. O diagnóstico e a análise das situações vivenciadas pela comunidade escolar indicaram serem urgentes mediar e auxiliar o coletivo da escola, a compreenderem e refletirem sobre os valores da comunidade, e acreditarem na capacidade de seus alunos e de seus pares. Por outro lado, as fragilidades que culminaram na vinda de um interventor à escola permitiram ao grupo redimensionar o pensar, reformulando suas ações pela compreensão do que a comunidade escolar (entendida aqui os alunos, pais, professores, equipe pedagógica, direção, funcionários) pode fazer para estimular a função social da escola. [...]. O levantamento da situação revelou muitos problemas estruturais, necessidade de diversas reformas e reorganização dos espaços pedagógicos, nova abordagem à Proposta Pedagógica que promovesse a melhoria nos altos índices de reprovação e evasão, e também, a falta de apoio da comunidade. Sendo a atuação do gestor escolar uma tarefa que perpassa várias dimensões, sejam elas administrativas, pedagógicas, políticas, sociais é urgente estar atento ao ato de compreender-se gestor e a partir dessa sensibilidade conduzir coletivamente a formulação do projeto pedagógico, agir na coordenação, acompanhamento e cumprimento das responsabilidades compartilhadas, ouvindo e dando sentido ao que a comunidade escolar tem a oferecer. [...] O momento era tenso e as relações pessoais estavam abaladas. Iniciamos investigando as causas dos conflitos, os valores da escola, as lideranças do grupo, a comunidade, entre outros. Iniciamos realizando um diagnóstico com análise da situação, os objetivos a alcançar, ajustar estratégias de receptividade ao grupo, melhorar o ambiente, criar empatia, pois não pertencíamos ao grupo, e construir um planejamento juntamente com toda a comunidade escolar para resolver os problemas. [...] Após o planejamento partimos para a ação. A experiência pautou-se na reconstrução do Projeto Pedagógico nas reuniões coletivas da escola, com encontros semanais. A cada semana a fala inicial era dada ao grupo para que narrassem suas expectativas, seus projetos, seu trabalho, e a partir da reflexão e da compreensão da história de cada um, constituiu-se um conjunto de ações, que compartilhados, uniram às metas e aos objetivos coletivos, mas também às responsabilidades individuais, a 
tarefa dada ao gestor foi articular responsabilidades individuais e coletivas de modo que todos tenham consciência de seu papel dentro da instituição de ensino, o que exigiu mais que aprender a compreender o outro, ensinar a importância de fazer-se compreendido.

\section{Saberes trançados por três fios entrelaçados}

A formação de professores, por muito tempo, e até hoje, continua se dissipando numa abordagem disciplinar, organizada em arcabouços epistemológicos engaiolados e sendo exercida continuamente a partir do quadro-negro. Totalmente desconexa da realidade ao dar ênfase exacerbada à teoria, com pouca preocupação de como esta reflete em cada realidade e em conformidade com o seu contexto cultural.

Conduzir os futuros professores e/ou em formação continuada, mediante o conhecimento dos fundamentos da profissão baseada nos sete saberes, por meio de observação da realidade, escuta sensível, pesquisa em profundidade, pensamento reflexivo, para intervir na realidade com ações concretas, projetos de vida, por soluções de caminhos alternativos decididos no coletivo, tendo em vista o restabelecimento de relações mais amistosas, a contínua troca de experiências, mediada por processos dialógicos capazes de integrar as partes ao todo e o todo às partes, é a condição humana a ser ensinada nos espaços formativos.

A condição humana é um dos fios dos sete saberes a serem trançados, entrelaçados com outros, para práticas formativas mais atuantes e menos passivas frente aos problemas sociais da vida. O saber "ensinar a condição humana" foi indicado por Marta, Lázaro e Maria como primeira prioridade entre os 7 saberes, e será, pois, o fio de análise da construção de um texto, cujo contexto da trama se desenvolve a partir dos fios entrelaçados.

\section{Fio 1. Ensinar a condição humana}

No exercício da práxis do saber "Ensinar a condição humana”, Morin (1999, 2007) alerta sobre a necessidade da consciência do conhecimento sobre o próprio conhecimento, pois este sempre comporta erro e ilusão, bem como, de um pensamento abrangente e mais articulado para uma compreensão mais adequada e 
consciente sobre os processos formativos e suas necessidades inerentes, mediante constantes releituras da realidade em conjunto com os pares. Além disso, importa a atuação dos sujeitos envolvidos na dinâmica da formação, por meio de um agir, em existência, com toda a inteireza, utilizando-se dos conhecimentos e das experiências apreendidas durante o viver/conviver.

Compreende-se que dessa tessitura construída e constituída nos mais diversos espaços de vida, de formação inicial e/ou continuada, perpassados, vividos e experienciados por sujeitos dispostos que desejam exercer a cidadania, podem emergir ações concretas, com transformações bem-sucedidas, pelo resgate dos sujeitos por meio de práticas mais dialógicas. Ou seja, um fazer desembocar ações particulares na direção do universal, com atitudes concretas. Assim como bem procedeu Marta, após ter se apropriado de novas epistemologias em espaços formativos, vivência na prática o saber "Ensinar a condição humana", ao levar os seus estudantes a uma imersão na realidade profissional futura, para conhecerem as suas condições reais e intervirem sem descontextualizar os sujeitos de sua cultura (LARAIA, 1986), numa tomada de ações em conformidade com as circunstâncias locais.

De forma também semelhante agiu Maria após ter elaborado diagnóstico para análise das situações vivenciadas pela comunidade escolar, mediado pelo exercício do diálogo para a compreensão dos problemas e reflexões no coletivo sobre os valores aparentemente "perdidos", visando ao resgate da credibilidade na capacidade de seus alunos e de seus pares e ao retorno destes como membros participantes e ativos na transformação da própria comunidade de aprendizagem.

A consciência epistemológica adequada do real, para a tomada de atitudes, consoante a escolhas políticas e estratégicas, como as de Marta e Maria, foram decisões-chave para a busca de vias de ação e de transformação nos espaços educativos considerados encarcerados, desacreditados, em verdadeiras ágoras. E o efetivo restabelecimento das relações comunicativas entre os membros da comunidade, com vistas à apropriação dos bens culturais da humanidade, mediante o resgate da convivência harmoniosa e humana entre os sujeitos.

Ao reintegrar os sujeitos da comunidade escolar (alunos, pais, professores, equipe pedagógica, administrativa e diretiva), a função social da escola é exercitada e reforçada pela participação ativa de cada um de seus membros, atribuída pelo 
sentido da importância do pertencimento, ao se colocar as experiências e vivências na reconstituição e humanização do todo, que se encontravam desconectados e fragilizados entre si, enquanto comunidade.

É fato que os espaços formativos não podem se “[...] constituir similares a um cárcere", como analogia intensificada e proferida metaforicamente pelo depoimento de Marta. Tampouco serem geridos e gestados à revelia, sem qualquer compromisso com o desenvolvimento humano a partir da compreensão de seus problemas singulares inerentes. A capacidade de pensar conjuntamente os problemas locais e globais, mediante a criação de espaços para o exercício da relação dialógica, que possibilitem os caminhos e as circunstâncias necessários para os sujeitos em formação abrirem-se ao inesperado, com consciência formada por meio de epistemologias mais abertas, para um agir em coletividade, é procedimento cada vez mais urgente e necessário, em função dos tempos atuais, fluidos e carentes de relações comunicativas mais humanizantes e humanizadoras.

Neste sentido, humanizar a convivência com o outro é da ordem do humano, e esta acontece na e pela cultura, perpassada pelo diálogo consigo, com o outro e com a vida. Do contrário, contribuiremos muito mais para a disjunção do que para a integração nos espaços formativos, reforçando a prática de ações antidialógicas, improdutivas, mutilantes e mutiladoras.

Reunir a comunidade escolar para uma escuta sensível sobre o que vivencia na dinâmica de sua comunidade de aprendizagem e de vida, cotidianamente, criando espaços dialógicos, conforme indicado pela narrativa de Maria, só demonstra e reafirma a "relevância da aproximação com o outro: escutar suas vozes, identificar suas necessidades", conforme assertiva por ela mesma proferida.

Relacionar-se para sentir-se integrado, portanto, é uma condição humana necessária para a prática dialógica que sugere abertura para o compartilhamento, troca de ideias e a construção de projetos interventivos de vida, com vistas à transformação da própria realidade numa simbiose homem/sociedade/natureza. Neste sentido, o conhecimento sobre os saberes da profissão professor (NÓVOA, 2016) interpelados e construídos no exercício de uma prática educativa concebida por meio da dialogicidade para perceber a realidade e nela intervir, requer ações em 
conformidade com as necessidades e circunstâncias de cada localidade, em conjunto com os seus pares, integrantes daquele microssistema.

A consciência da necessidade de uma escuta sensível do outro, de suas necessidades e sonhos, foi percepção fundamental, como reforçado também por Lázaro em sua narrativa, ao fazer opção por ouvir atentamente o que os seus alunos apresentavam como expectativas em relação à disciplina e quais eram os seus objetivos, como também o demonstrou Marta, ao ouvir atentamente os membros da comunidade escolar por meio da realização de diagnóstico para análise das situações vivenciadas, visando encontrar soluções conjuntas mediadas pelo diálogo.

Evidencia-se, assim, o quanto a comunicação intersubjetiva e os relacionamentos são condições humanas necessárias para o fortalecimento do sentimento de pertencimento e integração a uma comunidade para o convívio e desenvolvimento humano saudável.

Cada uma das iniciativas propostas por Maria, Marta e Lázaro para a reconstrução de processos de ensino e aprendizagem formativos — conforme propõe Nóvoa (2016), - contribuem para o exercício de práticas formativas baseadas na perspectiva dialógica, suscitando perguntas e respostas em conjunto e sob os mais diferenciados olhares, interpeladas, sobretudo pelo sentimento de esperança por soluções quanto aos problemas existentes, propulsionando saltos qualitativos à comunidade, ao se ter conseguido resgatar a participação ativa dos sujeitos.

A consciência epistemológica apreendida, exercitada pela prática do princípio da dialogicidade, como mediador da "costura" entre os saberes científicos e humanísticos, foi mister e significativa para o ensinar a condição humana (Fio 1), pois este saber requer o respeito às ideias contrárias e às certezas provisórias, cujas perspectivas e óticas em relação à vida são plurais e multidimensionais, quando se lida com grupos de visões heterogêneas.

E como assegura Morin (1999), nos momentos em que não é possível superar as contradições, vencer os antagonismos e ultrapassar os paradoxos, é preciso aprender a lidar e a conviver com os opostos, compreendendo-os, pois é nesse emaranhado da trama que emerge a complexidade, pois do mesmo lugar que surgem os problemas nascem também as suas soluções. E "o entrechoque de ideias, opiniões e comportamentos é uma das principais fontes de inspiração para a 
criatividade e a resolução dos problemas de convivência", como assegura Mariotti (2007, p. 151), para o enfrentamento das incertezas (Fio 2), mediante o ensinamento da compreensão (Fio 3).

\section{Fio 2: Enfrentar as incertezas}

A consciência sobre a própria ação pressupõe a consciência de um fazer compreendido em constante movimento de estado de evolução, alimentado por um pensar complexo e práticas pedagógicas congruentes com os pressupostos metodológicos menos tecnicistas e mais complexos, plurais e multidimensionais, com vistas à superação do distanciamento do professor do quadro negro (NÓVOA, 2016) e a imersão no mundo em rede, pela necessidade de que "é preciso aprender a conviver com as incertezas ligadas ao conhecimento" (MORIN, 2010, p. 82).

Porém, sem descontextualizar-se do mundo, tampouco de suas inovações e bens científico-culturais, mas buscando compreendê-los em sua própria dinâmica. É o que buscam traduzir as iniciativas de Maria, Lázaro e Marta, pois práxis é confronto. E confrontar é estar disposto a pensar o real para transformá-lo, confrontando-se o vivido com o pensado, pois a certeza do risco de sua incerteza é inerente a cada ação. Por isso é sempre desafio, e eliminá-la é impossível, pois “a imprevisibilidade reside no próprio cerne do determinismo” (MORIN, 2015, p. 41), requerendo, portanto, um constante negociar com a incerteza, pelo recurso à reflexão, combinando riscos e estratégias de precaução, mediante uma escuta vigiada, para propulsionar o movimento de aprendizagem e o seu desenvolvimento processual e contínuo.

E como assegura Morin (2015, p. 51), "é preciso aprender a navegar em um oceano de incertezas, através de arquipélagos de certezas". Para tanto, o exercício do diálogo intra e intersubjetivo é uma via para a possibilidade de se compreender o processo de formação dos sujeitos, mediante uma ética comprometida, valores concebidos e pelo respeito ao repertório cultural que constroem e trazem consigo durante a vida.

O pressuposto do diálogo não consiste em convencer o outro, mas abrir possibilidades para partilhar significados construtivos de conhecimentos, durante o 
viver e o conviver, para então se direcionar ao agir. Este agir, no sentido de criar ações interativas, pela percepção e conhecimento da realidade, mesmo mediante contextos complexos de diferenciados posicionamentos e ideias, pois estes e estas, ao serem articulados com os saberes apreendidos ao longo da vida, por seus diversificados membros em processos dialógicos, podem suscitar outras ideias criativas e vias de caminhos antes não pensados.

Dessa forma, a atitude dialógica possibilita emergir a comunicação, sem autoridade hierarquicamente estabelecida, numa perspectiva contínua e evolutiva de solidariedade e compartilhamento, por meio da construção de pensamentos baseados em saberes interconectados e integrados. Em um processo relacionalmente favorável, na busca por inovadoras possibilidades de conhecimento e apreensão da realidade, pela prática do diálogo, com flexibilidade e respeito às ideias do outro, de modo a assegurar a manutenção dos processos de fluxos dialógicos contínuos, circulares, e de constantes recursividades, como foi possível notar nos três relatos das experiências vivenciadas por Maria, Lázaro e Marta.

A reflexão sobre os fatos passados, remetendo para o futuro, os olhares dos sujeitos no presente, mesmo sem os fundamentos teóricos fortemente consolidados, mas já desabrochados — pela necessidade de um fazer pedagógico diferente retrata a necessidade da consciência sobre o próprio pensar e fazer, dos fundamentos implícitos a cada sujeito, orientadores de suas ações, reforçando-se assim o dito por Freire (1996), de que não há uma prática sem teoria e nem esta sem aquela. Ambas se imbricam, revelando o sujeito e suas epistemologias, trazendo-as à consciência para revê-las e ressignificá-las no presente, com posturas mais conscientes e fundamentadas, no sentido de se dar uma nova ordem ao que se mostra desorganizado e desconexo do real.

A partir do momento em que os professores são munidos por novos fundamentos e perspectivas metodológicas, como proposto pelos "Saberes Necessários à Educação do Futuro", no presente, espera-se que eles possam encontrar novas vias pedagógicas para além do quadro-negro, dos conteúdos engessados, e processos antidialéticos nos espaços formativos.

Distanciar-se de um processo formativo mais estático, compreendido numa perspectiva de meros repetidores de informações, como sugere Nóvoa (2016), 
requer por parte dos professores, atitude de autonomia e autoria para criar e protagonizar nos espaços educativos e para além destes, tendo em vista oportunizar aos membros da comunidade educativa saírem das próprias gaiolas epistemológicas, consideradas por D’Ambrósio (2009). Tal atitude foi bem encaminhada por Maria, ao levar os estudantes para conhecerem outras realidades, para além da sala de aula, e se apropriarem de conhecimentos provindos da realidade, mais pertinentes e munidos de sentido e significado, numa tentativa esperançosa de reverter a lógica reprodutivista e de passividade dos sujeitos nos espaços formativos, com vistas a avançar para uma perspectiva de formação com protagonismo docente.

Coadunar os momentos de teoria com o seu exercício na prática, pela vivência no campo profissional, permite aos sujeitos em formação pensar e repensar sobre a profissão, pela pesquisa, elaboração e desenvolvimento de projetos, para o acesso e maior proximidade com a cultura e seu repertório contemporâneo, apreendendo-a, pela observação, pelo diálogo e ações viáveis que possam revitalizar os espaços aparentemente "cinzentos" (sem vida), como dito por Maria.

Nas ações propostas por Maria e Marta, a exigência de novos itinerários pedagógicos formativos, a reaproximação dos sujeitos com a sociedade do século XXI - a partir de ações mais integradoras e coletivas — foi atingida pelo sentimento de pertencimento. Ao sentir-se pertencente a uma comunidade de diferentes fins, o sujeito passa a se relacionar, e, consequentemente, a agir, aprendendo, reaprendendo e se desenvolvendo em comunhão com os seus pares, em prol do bem viver, reafirmando assim que é na relação com o outro que nos constituímos, aprendemos e nos transformamos mediante as trocas de experiências vivenciadas no decurso do viver/conviver — pela condição de sujeito social que somos - mediados pelo diálogo. Dessa forma, nos transformamos conforme transformamos o mundo, e isso requer disposição, mesmo diante dos incertos e desafiadores processos educativos e de vida.

Paralelas à coragem e às "certezas" de possíveis transformações, emergem também a insegurança e as incertezas. No relato de Lázaro, por exemplo, urge a incerteza quanto aos conhecimentos de sua profissão que poderiam propiciar a motivação necessária para o atendimento aos interesses da turma, bem como quanto à escolha do método, e a insegurança quanto à sua efetividade, e se aquela seria a 
melhor via a ser trilhada. Destaca-se também a desconstrução da própria prática pedagógica, sinalizado por Lázaro ao expressar não se sentir preparado para inovar diante do inesperado.

Diante deste contexto, é fundamental aprender a aprender a lidar com os paradoxos: certeza e incerteza, ordem e desordem, segurança e insegurança, primando-se pelo equilíbrio e o restabelecimento da ordem, para novas desordens e reorganizações em espaços formativos. Desse movimento de relações aparentemente contraditórias, porém complementares, é que a vida mantém o seu ciclo em processo ativo de desenvolvimento e de produção, construindo-se, desconstruindo-se e reconstruindo-se o tempo todo. $\mathrm{O}$ reconhecimento do risco permite aos sujeitos um olhar mais profundo, com maior consciência sobre os problemas da vida tanto pessoal quanto socialmente, pelo processo de autoconhecimento (o aprender a ser), pelas experiências vivenciadas durante o viver, com vistas a enfrentar as incertezas presentes na dinâmica da vida (o aprender a conviver), para então se colocar o agir (o aprender a fazer).

Dessa forma, "Ensinar a condição humana" como primeira prioridade em espaços formativos é uma necessidade vital, pois requer a legitimação do outro, bem como o exercício da autopercepção enquanto pessoa, profissional, sujeito construtor da própria história, na relação com o outro, reconhecendo, de forma equilibrada, os próprios limites humanos das incertezas por suas ações, pois “em toda ação há escolha e risco" (MORIN, 2010, p. 42). Neste sentido, é mister "conceber a unidade que assegure e favoreça a diversidade, a diversidade que se inscreve na unidade" (MORIN, 2010, p. 55), pelo ensinamento da condição humana, entrelaçado pelo da compreensão para enfrentar as inúmeras incertezas em relação ao conhecimento e a vida.

\section{Fio 3: Ensinar a compreensão}

A consciência sobre a pluralidade cultural e multifacetada das instituições, que engloba, como frisa Marta, "diversas realidades socioeconômicas, emocionais e culturais; um ambiente heterogêneo por princípio", leva a valorizar as trajetórias de histórias de vida construídas e constituídas pelos sujeitos que compõem diferentes comunidades e suas diferenciadas culturas. É fazer com que os processos subjetivos 
se façam presentes e sejam centrais - para transformações por meio da manifestação dos potenciais adormecidos e antidialéticos - mediante o restabelecimento do diálogo, na coletividade, para ações locais concretas.

Uma disciplina em princípio teórica, segundo Maria, se transformou numa ágora de integração de saberes (gestão, artes, recreação), como também de integração da docência, da pesquisa e da extensão. E, sobretudo, "de culturas, biografias e esperanças de que naquela escola é possível aprender e resgatar o sentimento de pertencer à própria comunidade escolar”"

E uma intervenção, segundo Marta, que inicialmente poderia ter sido marcada por autoritarismos, posturas unilaterais e apartadas da trajetória da comunidade, constituiu-se em um movimento de aprender e, sobretudo, de ensinar a compreensão, enfrentando as incertezas provindas das soluções estabelecidas em conjunto. Isto porque toda a ação é imbuída de retroações, ou seja, de riscos que fogem ao controle humano. No entanto, sem correr riscos será impossível compreender o "problema importante (MORIN, 2007)", pois só se pode compreendê-lo, entregando-se ao aleatório, ao imprevisível, pois são estes os processos emergentes que possibilitam o crescimento e a evolução das relações comunitárias, na medida em que enfrentam junto o inesperado, pelo ensinamento da compreensão, arcando com as incertezas inerentes, em conformidade com as condições humanas e de respeito às realidades singulares.

No relato de Marta, "Ensinar a compreensão" tornou-se, por conseguinte, a base de todo o processo de intervenção à medida que, ao perceber o outro, abriu-se a possibilidade de atribuir novos significados à história da comunidade a partir da história de cada sujeito. Visto que todos nós trazemos diferentes repertórios culturais, conhecimentos incorporados, desejos e sonhos, e nessa escrita da própria história de vida, significá-la e ressignificá-la são o roteiro a ser considerado e respeitado para a apreensão de "conhecimentos pertinentes" (MORIN, 2010), a partir da releitura dos problemas emergentes.

Quando o sujeito é constantemente desafiado a intervir em sua comunidade, a partir da compreensão dos seus problemas inerentes, por um agir fortalecido pelo diálogo com o outro e outros, mediante consciências despertas, o diálogo e a ação 
em conjunto se tornam fundamentos necessários para o exercício de uma cidadania planetária civilizatória.

Bohm (2005, p. 77) assegura que "o compartilhamento de consciências é mais importante do que o conteúdo das opiniões". Acrescenta, ainda, que "a própria estrutura de um pressuposto ou opinião implica que eles devem estar abertos à demonstração de que podem não estar corretos". Por isso, o exercício do diálogo é atitude a ser desenvolvida nos espaços destinados à formação docente, para que no exercício futuro da profissão, os sujeitos do ensino possam exercê-la, e com protagonismo gestar soluções aos problemas emergentes, movidos sempre por uma prática fundamentada e desenvolvida na perspectiva dialógica. Para tanto, o agir pressupõe disposição ao risco, coragem para enfrentar as suas incertezas, e dar um salto na indeterminação, pela superação do pensamento unilateral, em um deverfazer irresistível em coletividade.

Assim, é fundamental a criação de espaços pedagógicos dialógicos, de escuta sensível ao outro, às suas ideias e opiniões, às suas histórias e trajetórias, colocando em suspenso todo e qualquer tipo de julgamento, em vista da possibilidade de abertura de novos caminhos de diálogo, visto que não há caminho único para a busca da verdade, pois todas as trilhas apontam para se chegar ao "não-caminho" (BOHM, 2005).

Vida e conhecimento, portanto, são indissociáveis no processo de aprender e de conhecer a realidade em quaisquer espaços formativos. Separar a história das ações biológicas e sociais do sujeito de seu contexto torna-se inviável, pois o sujeito se constrói nas relações dialógicas. É, pois, por meio desse imbricamento que o mundo aparece, à própria imagem e semelhança, como assim asseguram Maturana e Varela (2001).

Para tanto, é válido reforçar a importância do reconhecimento da diversidade das condições humanas presentes nos ambientes formativos e o respeito às suas diferentes histórias de vida. Desta forma, ao se perceberem reconhecidos, os sujeitos da dinâmica educativa poderão sentir-se parte de um todo bem maior que os engloba, aprendendo e ensinando na relação uns com os outros, mediados pelas trocas intersubjetivas de conhecimentos, na tentativa de enfrentar as incertezas 
presentes na vida para evoluir psicológica, afetiva e socialmente, pela compreensão uns dos outros.

Enfim, Ensinar a condição bumana, enfrentar as incertezas e ensinar a compreensão é fazer com que o sujeito se perceba como parte constitutiva dessa sociedade complexa, que não cabe em uma gaiola, capacitando o sujeito a enfrentar com autonomia suas incertezas a partir de um olhar para dentro de si mesmo, reconhecendo-se, tanto os professores quanto os estudantes, como protagonistas na dinâmica que envolve o viver e o aprender nos espaços de formação formalmente reconhecidos. É condição necessária para a construção da identidade profissional docente, humana e terrena, mantida e transformada na alteridade, possibilitada pelo diálogo (BUBER, 1987, 2001), no reconhecimento de si mesmo e do outro, de sua identidade a partir de sua construção histórico-cultural como sujeito pertencente a essa humanidade caminhante.

É importante reforçar que o exercício da dialogicidade vai além do encontro do sujeito com os saberes apreendidos nos espaços educativos formais. Constitui-se em um processo de retomada da voz interior dos sujeitos, do respeito aos seus valores construídos em comunidade e aos seus saberes produzidos, pois o diálogo é o propulsor e a conexão para o estabelecimento do elo entre o sujeito e a vida. De acordo com Freire (1987), é a essência constitutiva da educação como prática da liberdade, com responsabilidade, mesmo que relativa.

A criação e o fortalecimento de espaços para o exercício da dialogicidade ampliam as possibilidades de os sujeitos vivenciarem momentos de aprendizagens com mais solidariedade, constituindo-se e desenvolvendo-se humanamente, de forma respeitosa na dinâmica da formação de professores. Este processo é fundamental para a ocorrência de momentos de construção, desconstrução e reconstrução de significância e ressignificação, de produção de novas zonas de sentido, mediante relacionamentos saudáveis com o outro e os outros, legitimados pela presença do sujeito e da percepção de sua importância para a constituição de si mesmo, na coletividade, a ser processada e desenvolvida autopoieticamente.

A formação de professores compreendida e desenvolvida nessa perspectiva da dialogicidade reveste-se da autopoiese, cujo pressuposto de sua dinâmica visa aproximar relacionalmente sujeito e vida, pois no processo construtivo do 
conhecimento, o sujeito precisa estar em interação permanente consigo, com o outro e com o meio cultural. Em plena congruência e coerência com as próprias ideias, sem deixar perder seus valores inerentes.

As formas de sentir e ser (dialógico), pensar e saber (dialético) e de atuar e agir (dialogicidade) do sujeito perante a vida, pelo próprio jeito de apreender a realidade e de transformar o fazer, ao mesmo tempo em que o ser vai se reconstruindo, é processo que envolve um conjunto de relações complexas apreendidas e ressignificadas cotidianamente no decurso do viver/conviver. Estas atitudes são expressões da subjetividade, traduzidas como a síntese da singularidade e da individualidade humana construída e constituída no decurso da vida social e cultural, da dialogicidade estabelecida entre a subjetividade social (saberes intersubjetivos) e a subjetividade individual (saberes intra-subjetivos). Esta seria a fonte criativa em que fluem as ideias, as emoções, a identidade do sujeito, sua marca singular que o identifica e que o faz ser igual em meio às diferenças, e ser respeitado em sua pluralidade cultural e singular, enquanto cidadão participante de sua comunidade local/global.

\section{Considerações finais}

As instituições formadoras (públicas e privadas) ainda são os espaços formativos favoráveis para os atuais e futuros professores aprenderem e se desenvolverem em níveis de conhecimento, construírem e se constituírem mediante a apropriação da cultura em circulação. No entanto, requer dos próprios membros dessas comunidades que sejam sujeitos ativos, e em conjunto com seus pares, busquem as condições necessárias para que os processos de desenvolvimento ocorram na relação uns com os outros, respeitando-se a realidade situada. Engajados nas ações educativas, professores e estudantes, pais, direção, etc., permanentemente em relação, sintam-se corresponsáveis pelo crescimento de sua comunidade e coautores da cultura que os constituirá.

Nos espaços formativos compreendidos dessa forma, as relações e os processos educativos se alternam e se alteram, pois o aprender e o ensinar requerem envolvimento, motivos para um agir dos docentes, dos discentes e de todos os 
envolvidos, direta ou indiretamente, no convívio educacional. Além disso, é necessário estar atento aos interesses dos professores em formação, para que estes também estejam atentos aos interesses dos seus estudantes, identificando os seus problemas pertinentes e seus desejos. Isto, que exige sensibilidade por parte, também, dos responsáveis pelos processos formativos, sensibilidade para com a percepção do outro ao olhar o mundo, ao seu agir, pois dependendo das circunstâncias, estas podem limitar ou potencializar os sujeitos do ensino e da aprendizagem a seguirem em busca de alternativas que lhe possibilite criar para transpor o problema emergente.

Daí a importância de o(a) professor(a) — com consciência epistemológica — ser capaz de criar as condições necessárias para os sujeitos ascenderem em termos de conhecimento, abrindo-lhes possibilidades de caminhos, brechas para a apropriação dos bens culturais em relação ao zeitgeist (espírito de época), e de ajudálos a transformar os saberes (as informações apreendidas) em conhecimentos pertinentes, com significância e significado, e a construir e reconstruir novas "zonas de produção de sentidos" em relação ao conhecimento, para que possam alcançar as melhores soluções e alternativas para a superação dos problemas de sua comunidade educativa, em coletividade.

Mudar a cultura dos cursos de formação de professores, há tempos habituada com as formas convencionais de monólogos e discurso unilateral impregnados há séculos, não é tão simples assim. Requer coragem e muita disposição por parte de todo o corpo gestor escolar para superar a repetição de modelos e práticas já conhecidos.

A reorganização do espaço pedagógico, com foco na valorização das histórias de vida dos sujeitos e de suas relações de aprendizagem, tendo o diálogo como princípio fundante e regenerador, constitui uma das vias possíveis para propiciar as condições necessárias de gestão, valorizando-se os pensamentos e ações, para que possibilitem a concretude do fazer pedagógico revolucionário e transformador.

Assim, uma caminhada educativa construída e demarcada por um constante processo de reflexão, de escuta e compartilhamento de significados, por meio de ações concretas, ainda que certo do risco que a incerteza das escolhas pode despertar e desenvolver os princípios fundantes do diálogo: o ouvir, o compartilhar e o agir. 
Portanto, estar articulado pelos três fios da trança dos saberes que envolvem o ensinar a condição humana, o enfrentamento das incertezas e o ensinamento da compreensão - compreendidos a partir das dimensões: antropológica, epistemológica e pedagógica — suscita a condição de criar e recriar as utopias, abertura de possibilidades de produção de conhecimentos pertinentes, e percorrer caminhos inovadores na docência. Todo este procedimento mesclado pelo diálogo pode possibilitar relações humanas mais significativas, e promover processos de formação de professores numa perspectiva mais dialógica e solidária, mais saudável e humanizadora.

\section{Referências}

BARDIN, L. Análise de conteúdo. Lisboa: Edições 70, 2002.

BOFF, L. A águia e a galinha: uma metáfora da condição humana. Petrópolis: Vozes, 1997.

BOHM, D. Diálogo: comunicação e redes de convivência. São Paulo: Palas Athena, 2005.

BUBER, M. Sobre comunidade. São Paulo: Perspectiva, 1987.

BUBER, M. Eu e Tu. 8. ed. São Paulo: Centauro, 2001.

D'AMBRÓSIO, U. Transdisciplinaridade. 2. ed. São Paulo: Palas Athena, 2009.

FREIRE, P. Pedagogia do Oprimido. 17. ed. Rio de Janeiro: Paz e Terra, 1987.

FREIRE, P. Pedagogia da Autonomia: saberes necessários à prática educativa. 3. ed. São Paulo: Paz e Terra, 1996.

HABERMAS, J. Teoria do agir comunicativo. Racionalidade da ação e racionalização social. Trad. Paulo Astor Soethe. São Paulo: WMF Martins Fontes, 2012.

LARAIA, R. Cultura: um conceito antropológico. Rio de Janeiro: Zahar, 1986.

LEMOS, A. Cibercultura, tecnologias e vida social na cultura contemporânea. Porto Alegre: Sulina, 2004.

MARIOTTI, H. Pensamento complexo: suas aplicações à liderança, à aprendizagem e ao desenvolvimento sustentável. São Paulo: Atlas, 2007.

MATURANA, H.; VARELA, F. $A$ árvore do conhecimento: as bases biológicas da compreensão humana. 5. ed. São Paulo: Palas Athena, 2001.

MORIN, E. Ciência com consciência. 3. ed. Rio de Janeiro: Bertrand Brasil, 1999. 
MORIN, E. Da necessidade de um pensamento complexo. In: MARTINS, F. M; SILVA, J. M. Para navegar no século XXI: tecnologias do imaginário e cibercultura. Porto Alegre: Sulina/Edipucrs, 2000. p. 19-42.

MORIN, E. Introdução ao pensamento complexo. 3. ed. Porto Alegre: Sulina, 2007.

MORIN, E. A cabeça bem-feita: repensar a reforma, reformar o pensamento. 15. ed. Rio de Janeiro: Bertrand Brasil, 2008.

MORIN, E. Os sete saberes necessários à educação do futuro. 2. ed. Brasília: Unesco, 2010.

MORIN, E. Ensinar a viver: manifesto para mudar a educação. Porto Alegre: Sulina, 2015.

NÓVOA, A. Sete disposições necessárias ao educador do presente. In: Conferencia Internacional: Saberes para uma cidadania planetária. (palestra proferida), Fortaleza (CE), 27 de maio de 2016. Disponível em: <https://vimeo.com/169804242>. Acesso em: 25 nov. 2018.

UNESCO. Conferência Internacional: Saberes para uma cidadania planetária. 2016. Disponível em: <http://www.unesco.org/new/pt/brasilia/about-this-office/single-

view/news/international_conference_discusses_education_humanism_ethi/>. Acesso em: 23 maio 2016.

RECEBIDO: $21 / 06 / 2019$

APROVADO: 05/02/2020

RECEIVED: 06/21/2019

APPROVED: 02/05/2020

RECIBIDO: $21 / 06 / 2019$

APROBADO: 05/02/2020 